\title{
Applying Corporate Governance for Sustainable Development: An Empirical Investigation in Developing Economics Using Structural Equation Modeling
}

\author{
Prof. Dr. Tarek Taha Ahmed \\ Dean of the Faculty, Pharos University in Alexandria, Egypt
}

\begin{abstract}
Despite the positive impact of corporate governance on corporate performance has been widely recognized and many academic and practitioners considered it as a prerequisite for sustainable development and effective resources management, few works empirically addressed this phenomenon and academic literature has paid limited attention towards factors influencing corporate governance applications in the developing economics context. It focused mainly on governance regulation. In responding to this call, the current study aimed at helping to narrow the existing research gap in the literature and contribute to the accumulated knowledge through achieving the following interrelated objectives. (a) Provide further insights into the current state of relevant literature (b) investigate empirically the critical factors influencing applying corporate governance for achieving sustainable development (c) developing a structural equation model (SEM) for predicting these factors in the developing economics context and provide empirical evidence on its validity and relevance. A multi-stage research methodology was utilized, combining quantitative and qualitative methods to validate the research model and empirically test the hypothesized relationships. The developed questionnaire was pretested and feedback from the pre-test and the panel of experts used to revise the survey instrument. The reliability was assessed using Cronbach's alpha coefficients and the results showed an acceptable level for each construct. The hypothesized relationships have been tested using structural equation modeling. The evidence of a good fit, reliability and validity indicated that the measurement model deemed appropriate for testing the structural model that demonstrated highly explanatory power. The current study provided empirical evidences and validation for the existing specialized literature concerning corporate governance and added empirical weight to research addressing developing countries.
\end{abstract}

Keywords: Corporate Governance, Developing Economics, Governance Organizational Factors, Governance Perceptual Factors, Structural Equation Modeling, Sustainable Development.

\section{INTRODUCTION}

Corporate governance now has been widely recognized by many academic and practitioners as a prerequisite for sustainable development and effective resources management of firms, as well as gaining competitive advantage (e.g. Gupta et al., 2018; Tan et al., 2017; Turner et al., 2014; Fanta et al., 2013;). Governance differs from management in that management runs the business, while governance makes sure that it runs efficiently and in the right direction (Tricker, 2012; Muller et al., 2016). Many of the most influential publications refer to governance as a control system with the aim of balancing organizations' economic, social and communal objectives (e.g. Muller et al., 2016; Tayan, 2011).

In this regard, Akbar et al. (2016); Zabri et al. (2016) and Chauhan et al. (2016) emphasized that the impact of corporate governance on corporate performance has been the main theme of many research projects in management literature and considered as a tool for protecting 
stakeholders' rights. Further studies support this observation, For example, Fanta et al. (2013) reported that governance is essential due to the separation of ownership and control, as owners delegate decision-making rights to managers, and managers may not make their decisions to the best interest of owners and engaged in self-interest, thus applying governance can minimize this conflict of interest.

Adegbite (2012) and Ilukor et al. (2015) arrived at same conclusion they concluded that applying governance is one of the most effective tools to minimize corruption in organizations operating in developing countries. Other authors (e.g. Asongu and Tedika, 2016; Andres and Asongu, 2013) indicated that governance is being the most effective weapon in the fight against corruption and conflicts of interest in organizations. Also, Okpara (2012) added the effective governance is significant for organizations in developing countries because it can lead to managerial excellence and help firms with a weak governance structure to raise capital and attract foreign investors.

Tofan et al. (2015) summarized some benefits of corporate governance, they indicated that governance can assist companies to meet the challenges of the modern business environment, improve decision-making and decisions quality, enhance performance, operations, competitiveness, profitability and long-term value and expand in a sustainable manner.

As noted from the above discussion many firms, specifically in developing countries, experience different factors in their attempt to apply corporate governance. However, these factors are not satisfactory addressed and in academic literature and there are limited works empirically or quantitatively examined this phenomenon to determine theses significant influencers which needed to be appropriately highlighted (Turner, 2014; Agyemang et al., 2013). Therefore, there would seem to be some merit for more studies to examine empirically factors that influencing applying corporate governance for achieving sustainable development and more effective resources management, and the current research is an attempt at this direction.

\section{RESEARCH PROBLEMS, OBJECTIVES AND PLAN}

Despite the number of governance articles has been increasing in the last decade and it is now widely recognized that applying corporate governance can lead firms to achieve sustainable development and gaining competitive advantage, through efficient and effective use of resource management and performance, limited literature has addressed factors influencing applying corporate governance. Moreover, gapes remain due to the few researches or case studies examined this phenomenon empirically in developing economics context (e.g. Asongu and Nwachukwu, 2016, Agyemang et al., 2013; Ilukor et al., 2015; Chalevas and Tzovas, 2010; Turner et al., 2014; Gyamfi et al., 2015; Pittman and Armitage, 2016).

In responding to this call, the current study aimed at helping to narrow the existing research gap in the literature and contribute to the accumulated knowledge through achieving the following interrelated objectives. (a) Provide further insights into the current state of relevant literature $(B)$ investigate empirically the critical factors influencing applying corporate governance for achieving sustainable development (C) developing a structural equation model (SEM) for predicting these factors in the developing countries context and provide empirical evidence on its validity and relevance..

With these objectives in view, the current research has been organized as follows: the literature and relevant studies were reviewed and analyzed. Then a research model was proposed and hypotheses were formulated to be tested in the study. 
This was followed by an explanation of the procedures used to obtain empirical data, measurement, and validation processes, as well as the testing of the hypotheses stated. Finally, based on paper's findings a series of conclusions with practical and academic implications and final thoughts that emphasize the great interest in the topic under analysis were presented, and then certain limitations and future lines of research with regard to this issue were highlighted.

\section{LITERATURE REVIEW AND DEVELOPING HYPOTHESES}

Relevant literature, which provided the conceptual foundation and theoretical background for this paper, and past researches were extensively and systematically reviewed in order to develop more effectively the study hypotheses and the proposed model. The literature review employed here followed a four-step process that has been adopted and tested in similar studies (e.g. Pittman and Armitage, 2016). (a) Research questions were determined to guide the review; (b) search protocol was developed to explore literature databases; (c) the results of the literature search were screened based on a predetermined set of criteria; and (d) the remaining literature was analyzed and synthesized. Through this process, it was noted that the majority of articles do not define governance, despite using the term, and the others documented the concept in different definitions (e.g. Pittman and Armitage, 2016). For brevity, we focused the discourse to the following definitions from recent related literature as this paper takes the lasted perspectives.

According to Muller et al. (2016) corporate governance is often defined as the means by which organizations are directed. Tofan et al. (2015) agreed with this concept they indicated that corporate governance is about striking a balance between achieving organizational objectives/aims and complying with applicable regulations, ethical norms, and contracts.

In contrary, others such as Agemeng et al. (2013) and Castellini \& Agemeng (2012) pointed out that corporate governance could be defined as the application of a set of powerful instruments in an organization to ensure an efficient and effective use of resources for achieving its main objectives as well as maximizing positive influence on other stakeholders. Similarly, Lamm (2010) defined corporate governance as the use of formality, thoroughness and transparency to an amalgamated structure of organization policy in order to ensure that only prudent risks are taken by the organization to achieve shareholder value as well as to succeed in the market. Termeer et al. (2016) presented a different perspective they viewed corporate governance as the interactions between public and/or private actors ultimately aimed at addressing collective issues.

In this connection, the institute of internal auditor of Netherlands (2016) indicated that corporate governance is all about directing and managing the company, its policies, structures, processes and procedures to realize the objectives of the company and its main stakeholders. These mentioned definitions are consistent with the concept adopted by Turner et al. (2014), they defined corporate governance as the structures and processes that determine how decisions are made, power is exercised and responsibilities allocated.

On the other hand, many of the most influential publications refer to corporate governance as a control function with the aim of balancing organizations' economic and social objectives and the individual and communal objectives. Examples include Larcker and Tayan (2011). A parallel stream of literature has argued that governance, representing a shift from hierarchical top-down government to structures that include non-statutory actors as decision makers (Furmankiewicz and Walsh, 2016). Within this context, Ojo and Mellouli (2016) indicated the term corporate governance has been used in a variety of ways, but is most often presented as 
an attempt to improve coordination for the purpose of solving problems. Thus, it can be differentiated between two corporate governance perspectives. The narrow perspective focuses on the relationships between corporate managers, a company's board of directors, and its shareholders. on the other hand, the broad perspective describes encompass the relationship of the corporation to all of its stakeholders and society, and cover the sets of laws, regulations, listing rules, and voluntary private-sector practices that enable corporations to attract capital, perform efficiently, generate profit, and meet both legal obligations and general societal expectations.

For the purpose of the current study, the second perspective of governance was adopted, and the corporate governance was operationally defined as a managerial approach involving principles, rules, procedure sand processes by which corporate activities are directed and managed to achieve sustainable development. The current study followed the description and the measurements of corporate governance constructs presented by earlier works such as Kisingo et al., 2016; Turner et al. (2014), Agyemang et al. 2013; Nofiantia and Suseno, 2014; and Devney, 2016). For example, transparency refers to which extend the reason behind decisions is event, open channels of communication, and accessible information to those who will be affected and reasoning behind. While accountability involves the obligation to supply achievement and failure reports to delegated authority.

Of particular interest to this study is to build and extend the recent previous works, thus we identified and analyzed two underlying dimensions which together integrated the most critical factors cited in the available literature that considered to have relationships with applying corporate governance into one comprehensive framework subject to examination for validation and relationship. Therefore, the structural research model contained variables that have not been examined simultaneously in previous studies.

The first dimension focused on organizational factors, namely corporate size, stakeholders pressure, top management support (Alreemy et al., 2016; Adegbite, 2010; Tofan et al., 2015), employees resistance (Ghizema, 2010), corporate ownership structure (Tofan et al., 2015; Adegbite, 2012; Chizema, 2010), organization corruption-control system (Asongu and Nwachukwn, 2016; Adegbite, 2012; Asongu, 2016), and conflict of interest (Fanta et al., 2013). While the second dimension concerned with perceptual factors such as perceived transparency, perceived accountability, and perceived fairness (Turner at al., 2014; Kisingo et al., 2016).

Drawing upon the comprehensive review of the specialized literature, which demonstrated the most factors that had been utilized by previous studies, and taking into account the theoretical background discussed earlier, as well as the data collected from qualitative study in the preliminary stage of our current study, the following hypotheses that guide the investigation were formulated for testing their relationships:

\section{I-Organizational Hypotheses}

$\mathrm{H}_{1}$ : Corporate' size positively influences the intention to apply corporate governance.

$\mathrm{H}_{2}$ : Corporate corruption-control system positively influences the intention to apply corporate governance.

$\mathrm{H}_{3}$ : Stakeholders pressure positively influences the intention to apply corporate governance.

$\mathrm{H}_{4}$ : Employee resistance to change negatively influences the intention to apply corporate governance.

$\mathrm{H}_{5}$ : Conflict of interest negatively influences the intention to apply corporate governance.

$\mathrm{H}_{6}$ : The application of corporate governance is associated with corporate ownership structure 


\section{II-Perceptual Hypotheses}

$\mathrm{H}_{7}$ : Perceived transparency positively influences the intention to apply corporate governance.

$\mathrm{H}_{8}$ : Perceived Accountability positively influences the intention to apply corporate governance.

$\mathrm{H}_{9}$ : Perceived fairness positively influences the intention to apply corporate governance.

\section{CONSTRUCTING THE STRUCTURAL ANALYTIC MODEL}

In this paper, a structural research model was developed through the integration of the constructs mentioned in the previous hypotheses, which incorporated many of the relevant features of corporate governance identified in literature to be examined simultaneously in one framework for validation. The strength of the hypothesized relationships embedded in the model and its robustness of predicting corporate' intention to apply governance for sustainable development.

Therefore, our research model contained 10 constructs, nine independent variables (organization's size, corporate' internal corruption-control system, stakeholders pressure, employee resistance to change, conflict of interest, corporate ownership structure, perceived transparency, perceived Accountability and perceived fairness) utilized as predictors of the criterion dependent variable intention to apply corporate governance for sustainable development.

Structural equation modeling (SEM) was adopted in our data analysis to provide efficient estimation for separate multiple regression equations estimated simultaneously where constructs could be represented by a summed scale and assess the relative importance of each construct.

Thus, the initial prediction multiple regression equation (EG1) of the research model can be presented as follows:

$$
\begin{aligned}
& Y_{\mathrm{Int}}=a+b_{\text {Csize }} C \text { Size }+b_{\text {Corr }} \operatorname{Corr}+b_{\text {Stak }} \operatorname{Stak}-b_{E m p R} E m p R+b_{o_{w n S}} \text { OwnS }-b_{\text {ConI }} \operatorname{ConI}+b_{\text {PTran }} \\
& \text { PTran }+b_{\text {Pacc }} \text { Pacc }+b_{\text {PFar }} \text { PFar }
\end{aligned}
$$

Where:

Csize $=$ Corporate' size

Corr $=$ corruption - control system

Stak $=$ Stakeholders pressure

EmpR= Employee resistance

OwnS= Corporate ownership structure

ConI= Conflict of interest

Ptran= Perceived transparency

Pacc $=$ Perceived accountability

Pfar= Perceived fairness

$\mathrm{Y}_{\text {Int }}=$ Corporate' Intention to apply governance

Overall, the evidence of a good model fit, reliability, and convergent validity indicated that the measurement model was appropriate for testing the structural research model. However, the measurement items used to operationalize these constructs were derived from previous relevant works and the wording of the items was adjusted to match the present context. 


\section{Research Methodology}

A richer research methodology is used in this empirical study combining quantitative and qualitative methods to validate the research model and empirically test the hypothesized relationships among its variables. Thus, the research process involved multi-stage procedures as follow.

\section{Preliminary Qualitative Study}

Preliminary qualitative study data were gathered by methods of focus group, complemented by a series of in-depth face-to-face interviews with ten chief executive officers of famous Egyptian companies to gain deeper understanding of the phenomenon under consideration, supports hypotheses development and establishes the criteria and relationship constructs relevant to our empirical study. Issues arising from this stage were used as a basis for the subsequent quantitative study.

\section{Quantitative Research Design}

Furthermore, a quantitative research study in the form of questionnaires was conducted in two stages, first the pilot survey was administrated during September 2016 to test the questionnaire's reliability, and second a cross-sectional national sample survey for data collection was conducted during October to December 2016. The target population was chief executive officers and general managers of Egyptian corporate firms operating at Alexandria Governorate, using simple random sampling technique to gain as many representative samples as possible and increase generalizations of the results.

The directory of Egyptian companies at the Egyptian ministry of trade and industry' website (http://www.tpegypt.gov.eg/ENG/EgyDirectory.aspx) served as a sampling frame for this study. Among a total of 350 questionnaires that were randomly distributed, 154 valid responses were obtained and used in data analysis, after removing invalid answers, yielding a usable response rate of 44.00 percent for the overall survey. The respondents did not need assistance in completing the questionnaires as the information on the cover letter and instructions on how to fill the questionnaire were explicit.

\section{Instrument, Validity and Reliability}

Before the full-scale survey, the present study took steps to ensure reliability and validity. The scales used for measurement process were adapted from well-established survey items of previous works and modified to suit the purpose of the current study. All research variables were measured by multiple items scales. A 7-point multi-item Likert scale ranging from 1-7 has been utilized for all constructs except corporate ownership structure (measure by 3-point scale) and all items included in the questionnaire were cross-validated before they were added.

The questionnaire was pre-tested and then followed by a pilot test to validate the instrument prior to conducting the survey with the actual population. In the pre-test, the respondents were asked to comment on listed items regarding the research constructs, including instrument length, questions format, the wording of scales, and other comments on how the questionnaire could be improved. The pilot test aimed to ensure that questionnaire adequately addressed the relevant issues and reducing possible ambiguity in the questions. Based on pretest and pilot test feedback, modifications had been made to improve readability and appropriateness. The revised questionnaire was again pre-tested and the final version was found worked well and the instrument has confirmed content validity. Subjects who participated in the pilot test were excluded from the subsequent study. 
The Cronbach's alpha coefficient test was used to evaluate the internal consistency reliability. The reliability analysis results exhibited an acceptable level, the value of Cronbach's alpha of every construct is greater than 0.8 (ranging from 0.84 to 0.93 ). Also, exploratory factor analysis was used to evaluate the construct validity and the results demonstrate acceptable standard.

\section{DATA ANALYSIS, MODEL TESTING AND RESULTS}

The empirical data collected by the survey was analyzed and tested using statistical software packages (SPSS). The analysis included descriptive statistics, correlation to examine the relationships among variables, multiple regression analyses with its associated statistical inference tests were applied due to the presence of many predictors in the study, to test for the joint and independent influence of predictors on the criterion variable.

Stepwise forward inclusion techniques of regression analysis were performed to assess the relative importance of predictor variables mentioned earlier and to select a smaller subset of variables that account for most of the variation in the criterion variable, as it does multiple regression a number of times, each time removing the weakest correlated variable.

Before running the inferential statistical analysis, the variance inflation factor test (VIF) was done and the total correlation matrix was reviewed in-depth to determine whether any multicollinearity effects among the independent variables included in the model equations. The results revealed that there was no severe multicollinearity problem among the regressors, which suggested that data was qualified for regression analysis and predictors were tolerated in the criterion variable. The results of testing each of the hypotheses are given below.

The summary output of the stepwise regression analysis (forward inclusion) introduced in table 1 led to accept the hypotheses $\left(H_{1}, H_{6}, H_{7}\right.$, and $\left.H_{8}\right)$ while the statistical significance test supported this acceptance and confirmed the hypothesized relationships. A strong significant and meaningful correlation is found between criterion variable $Y_{\text {Int }}$ and the above mentioned predictor variables (Multiple $R$ "model $4 "=0.910)$. The value of $\mathrm{F}$ - ratio "model $4 "(F(4,149)$ $=179.248$ at $p<0.000000000$ ) is statistically significant indicating that the results of the model are highly significant and the its goodness-of-fit considered satisfactory.

Table 1 Summary output of the stepwise regression analyses (forward inclusion)

\begin{tabular}{|c|c|c|c|c|c|c|c|c|c|}
\hline Model & $\mathrm{R}$ & $\mathrm{R}^{2}$ & Adj. $R^{2}$ & $\mathrm{SS}_{\text {reg }}$ & $\mathrm{SS}_{\text {res }}$ & $\mathrm{SS}_{\text {total }}$ & $\mathrm{df}$ & $\mathrm{f}$ & Sig. \\
\hline 1 & $0.853^{\text {a }}$ & 0.728 & 0.727 & $\begin{array}{c}268.76 \\
5\end{array}$ & $\begin{array}{c}100.2 \\
29\end{array}$ & 368.994 & 1,152 & 407.590 & $\begin{array}{c}0.000000 \\
0\end{array}$ \\
\hline 2 & $0.904^{b}$ & 0.817 & 0.815 & $\begin{array}{c}301.53 \\
6\end{array}$ & $\begin{array}{c}67.45 \\
8\end{array}$ & 368.994 & 2,151 & 337.485 & $\begin{array}{c}0.000000 \\
0\end{array}$ \\
\hline 3 & $0.907^{c}$ & 0.823 & 0.819 & $\begin{array}{c}303.69 \\
1\end{array}$ & $\begin{array}{c}65.30 \\
3\end{array}$ & 368.994 & 3,150 & 232.525 & $\begin{array}{c}0.000000 \\
0\end{array}$ \\
\hline 4 & $0.910 \mathrm{~d}$ & 0.828 & 0.823 & $\begin{array}{c}305.50 \\
5\end{array}$ & $\begin{array}{c}63.48 \\
8 \\
\end{array}$ & 368.994 & 4,149 & 179.248 & $\begin{array}{c}0.000000 \\
0\end{array}$ \\
\hline \multicolumn{10}{|c|}{$\begin{array}{l}\text { a. Model1: Predictors Variables entered: (constant), Csize } \\
\text { b. Model2: Predictors Variables entered: (constant), Csize, OwnS } \\
\text { c. Model3: Predictors Variables entered: (constant), Csize, OwnS, Pacc } \\
\text { d. Model4: Predictors Variables entered: (constant), Csize, OwnS, Pacc, Ptran } \\
\text { Criterion Variable: } Y_{I A C C}\end{array}$} \\
\hline
\end{tabular}

The coefficient of determination, multiple R-square suggested that the proposed model is valid, the predictor variables of the model explained the major proportion $(82.80 \%)$ of the variability observed among the criterion variable $Y_{\text {Int }}\left(R^{2}\right.$ "model $\left.4 "=0.828\right)$, which reinforce our confidence in the hypotheses testing results and provides support for the above mentioned association. Furthermore, the adjusted $R^{2}$ of model 4 , which is a more conservative estimate of 
variance by considering error variance, is 0.823 . This reinforces our confidence that the overall explanatory power of the research model considered high and quite capable of explaining the observed variance among the sample.

As seen from table 1 among 9 predictor variables included in the initial equation (EG1), only 4 variables (Csize: corporate size, OwnS: corporate ownership structure, Pacc: perceived accountability and Ptran: Perceived transparency) were found to have a critical significant impact on the criterion variable $\left(Y_{\text {Int }}\right.$ : Corporate intention to apply governance for sustainable development). They succeeded in entering into "model 4" equation. The stepwise technique determined which of the initial 9 constructs should be included as predictors in the final equation.

Nevertheless, tracing the order in which these variables have been entered the equation suggested that corporate size (Csize) specifically considered the most critical motivating factor for applying governance, it has the most significant impact on corporate' intention to apply governance for sustainable development. This factor alone explained 72.80 percent of such total variation $\left(R^{2}\right.$ "model $\left.1 "=0.728\right)$, implying that that more large corporate size, the more intention to apply governance. This conclusion is graphically presented in figure 1.

Figue 1: The Line Fit Plot



As seen the line fit plot illustrated that the variation around the estimated regression line is constant suggesting that the assumption of equal error variances is reasonable and there is a strong linear relationship between Csize and Yint. On the other hand, the final step analysis of the multiple regression stepwise "model 4" excluded the other 5 variables (Corr = corruptioncontrol system, Stak: stakeholders pressure, EmpR: Employee resistance, ConI: Conflict of interest and Pfar: Perceived fairness) for their less significant impact. For easily comparing and assessing the relative impact of each predictor variable on the criterion variable, standardized beta coefficients $(\beta)$ and t-test values of the 4 variables that succeeded in entering into "model $4 "$ were presented in table 2 . 
Table 2: Standardized and non-standardized coefficients of variables

\begin{tabular}{|c|c|c|c|c|c|c|}
\hline \multirow{2}{*}{$\begin{array}{l}\text { Predictor } \\
\text { a } \\
\text { "Model 4" }\end{array}$} & \multicolumn{2}{|c|}{$\begin{array}{c}\text { Non-standardized } \\
\text { Regression } \\
\text { Coefficients }\end{array}$} & \multicolumn{2}{|c|}{$\begin{array}{c}\text { Standardized Beta } \\
\text { Coefficients }(\boldsymbol{\beta})\end{array}$} & \multicolumn{2}{|c|}{$t$-test } \\
\hline & Symbol & Value & Symbol & Value & Value & Sig. \\
\hline Csize & $B_{\text {Csize }}$ & 0.506 & $\boldsymbol{\beta}_{C B C}$ & 0.509 & 9.505 & $0.000000^{*}$ \\
\hline OwnS & $B_{\text {OwnS }}$ & 0.774 & $\boldsymbol{\beta}_{P C R}$ & 0.367 & 7.736 & $0.000000^{*}$ \\
\hline Pacc & $B_{\text {Pacc }}$ & 0.446 & $\boldsymbol{\beta}_{S T P}$ & 0.301 & 3.314 & $0.000000^{*}$ \\
\hline Ptran & $B_{\text {Ptran }}$ & 0.312 & $\boldsymbol{\beta}_{P O E}$ & 0.298 & 2.964 & $0.01000^{* *}$ \\
\hline Intercept & $\mathrm{A}$ & 0.598 & & & & \\
\hline
\end{tabular}

The finding shown in table 2 is consistent with the results summarized in table 1 . Corporate size (Csize) had the highest corporate' intention to apply governance for sustainable development $\left(Y_{\text {Int }}\right)$ with positive association (highest Beta value: $\beta_{\text {Csize }}=0.509$, and highest $t$-test value: $t=9.505, p<0.000000)$, corporate ownership structure $\left(\beta_{\text {owns }}=0.367, t=7.736\right.$ $p<0.000000$ ). The values of the non-standardized regression coefficients in table 2 were utilized for mathematically predicting corporate' intention to apply governance by the following final research equation (EQ2), while table 3 provides a brief summary of structural model results.

$$
Y_{\mathrm{Int}}=-0.598+0.506 \text { Csize }+0.774 \text { OwnS }+0.446 \text { Pacc }+0.312 \text { Ptran-------(EG2) }
$$

Table 3: Structural Model Result

\begin{tabular}{|c|c|c|c|}
\hline Hypotheses & $\begin{array}{l}\text { Structural } \\
\text { Paths }\end{array}$ & $\begin{array}{c}\text { Standardized } \\
\text { Beta Coefficients }\end{array}$ & Results \\
\hline$H 1$ & Csize $\longrightarrow$ YInt & $0.509^{*}$ & Supported \\
\hline$H 2$ & Corr $\longrightarrow$ YInt & Excluded & Not supported \\
\hline$H 3$ & Stak $\longrightarrow$ YInt & Excluded & Not supported \\
\hline$H 4$ & $E m p R$ & Excluded & Not supported \\
\hline$H 5$ & OwnS & $0.367^{*}$ & Supported \\
\hline$H 6$ & $\longrightarrow Y I n t$ & Excluded & Not supported \\
\hline$H 7$ & $\rightarrow$ YInt & $0.298^{* *}$ & Supported \\
\hline H8 & Pacc $\longrightarrow$ YInt & $0.301^{*}$ & Supported \\
\hline H9 & PFar $\longrightarrow$ YInt & Excluded & Not supported \\
\hline
\end{tabular}

The results of descriptive analysis in table 4, showed that there is milder corporate intention to apply governance in developing economics context (Mean: $\overline{\mathrm{x}}=3.72077922077922$ out of 7 , Standard Deviation: $\mathbf{S D}=1.55297207465667$, and Skewness=0.200575518643555). This response revealed that not corporate top-management levels valued the significant of corporate governance. 
Table 4: Descriptive Analysis

\begin{tabular}{|c|c|c|c|c|c|c|}
\hline$N$ & Minimum & Maximum & Mean & Standard & \multicolumn{2}{|c|}{ Skewness } \\
& & & & Deviation & \multicolumn{2}{|c|}{} \\
\cline { 6 - 7 } Statistic & Statistic & Statistic & $\overline{\mathrm{x}}$ & SD & Statistic & Std. error \\
\hline 154 & 1 & 7 & 3.720779 & 1.552972 & 0.200575 & 0.195532 \\
\hline
\end{tabular}

The Normal P-P plot of regression standardized residual test for assessing the assumption of normality was conducted, as shown from figure 2, our data met the assumptions of normality. The plot points fell nearly on a straight line, supporting the condition that the error terms of data used in this research are approximately normally distributed and the fitted model is appropriate.

Figure 2: Normal P-P plot of regression standardized residual

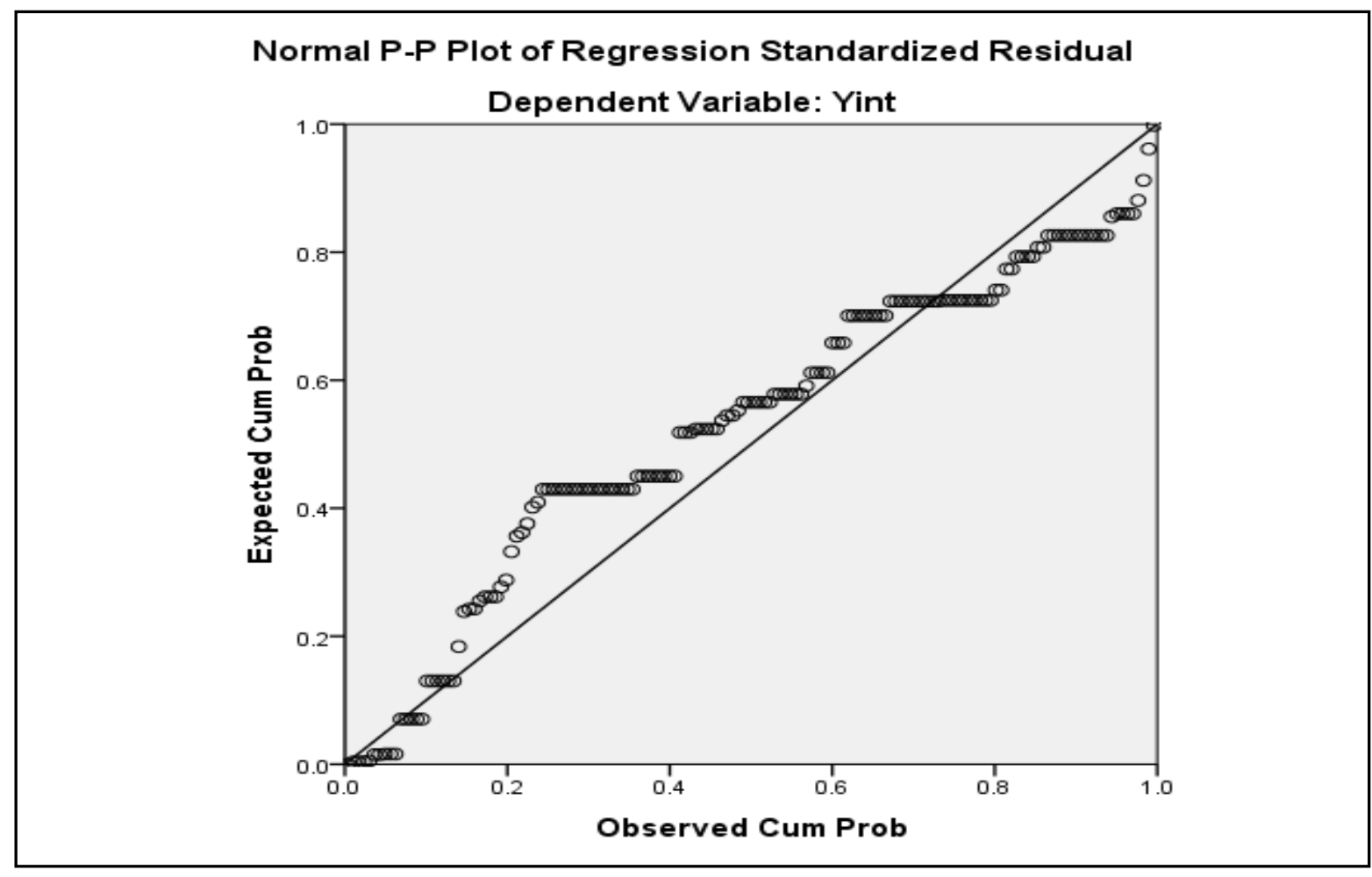

\section{CONCLUSION AND IMPLICATIONS}

This paper has taken a further significant step in contributing to both theory and practice of corporate governance, and to help address some gaps in the current body of literature. More specifically, this study has made a number of important practical (managerial) implementations and theoretical (academic) contributions. In term of practical implications, the present research has attempted to enhance current understanding of corporate governance implementation in developing economics context with a particular focus on Egypt as an example. The current study appropriately highlighted the importance for applying corporate governance as a pressing need to gain sustainable development, and found that the most critical motivating factors influencing corporate' intention to apply governance in developing economics context, according to their relative importance are corporate size, corporate ownership structure as organizational factors and perceived accountability, perceived transparency as perceptual factors. Thus, it is recommended that these factors should be taken in consideration when formulating governance application strategies or any corporate governance regulatory direction for firms across different institutional environments to gain sustainable development. 
However, the empirical findings revealed that corporate size specifically considered the most critical motivating factor for applying governance, it has the most significant impact on corporate' intention to apply governance, implying that that more large corporate size, the more intention to apply governance.

From an academic and research standpoint, this study provided empirical evidences and validation for the existing specialized literature concerning corporate governance and added empirical weight to research addressing developing economics. The findings of the empirical study provide support for the research model and for the hypotheses regarding the directional linkage among its variables. The research model was tested using SEM and results indicated support to the model. The high overall explanatory power of our model indicated that this model is capable of explaining high proportion of the variance observed in the Egyptian firms.

As, the current study attempted to integrate and encompass the most frequently cited constructs in the relevant literature, and applied them in the developing economics context in order to best examine the phenomenon, which have never been integrated before into one framework subject, to examination for validation and relationship. Therefore, the research model contained variables that have not been tested simultaneously in previous works.

\section{LIMITATIONS AND FURTHER RESEARCH}

To make the research findings more objective, few limitations that present opportunities for future research should be discussed. First, the research model was validated using empirical data gathered from Egypt and therefore the findings may be affected by the culture in this developing country. Since the study is cross-sectional in design, a further examination of our argument using a longitudinal study is recommended in the future to investigate our model in different times.

Although the majority of the hypothesized relationships were validated, and significant, and our structural model yielded a relatively high level value of multiple correlation coefficient, the obtained value of multiple R-square $\left(R^{2}\right)$, implies that other additional variables, which may not be considered in our research model, can be addressed to enhance the model ability for prediction.

It is beyond the scope of this paper to study other determinants of corporate governance barriers or challenges, which may have some implication on our findings, so addressing this aspect is left to future research. However, there are other opportunities to build on this study in future research. Suggested areas include re-examining the proposed model in other countries with different cultures, and make comparisons, to see whether it can be applied, or whether the same factors turn out equally significant. It would be valuable that future research use other theoretical bases or different methodologies and sample to derive different predictions.

\section{ACKNOWLEDGEMENTS}

The author would like to express thanks for chief executive officers and general managers of Egyptian corporate firms operating at Alexandria for helping data collection without which this empirical study would not have been possible. The author is also very grateful for the insightful feedback and valuable comments on earlier draft during development of this paper.

\section{References}

Adegbite, E. (2012). Corporate governance regulation in Nigeria, Corporate Governance: The International Journal of Business in Society, Vol. 12 Iss. 2, pp. 257 - 276 
Ahmed, T. T. (2018). Applying Corporate Governance for Sustainable Development: An Empirical Investigation in Developing Economics Using Structural Equation Modeling. Advances in Social Sciences Research Journal, 5(3) 479-491.

Agyemang, O., Aboagye, E. and Ahali, A. (2013). Prospect and Challenges of Corporate Governance in Ghana, International Journal of Scientific and Research Publications, Volume 3, Issue 5, pp 1-8.

Akbara, S., Hughesa, J., El-Faitouri, R., Zulfiqar, S. and Shah, A. (2016). More on the relationship between corporate governance and firm performance in the UK: Evidence from the application of generalized method of moments estimation, Research in International Business and Finance, 38, pp 417-429

Alreemy, Z. Chang, V., Walters, R. and Wills, G. (2016). Critical success factors (CSFs) for information technology governance(ITG), International Journal of Information Management, 36, pp 907-916

Andrés, R. and Asongu, S. (2013). Fighting software piracy: which governance tools matter inAfrica? J. Bus. Ethic., 118(3), pp 667-682.

Asongu, S. (2016).Determinants of growth in fast developing countries: evidence from bundling and unbundling institutions, Polite Policy, 44, (1), pp 97-134.

Asongu, S. and Nwachukwu, J. (2016). The role of governance in mobile phones for inclusive human development in Sub-SaharanAfrica, Technovation 55-56, pp 1-13

Asongu, S. and Tedika, K. (2015). Is Poverty in the African DNA (Gene)?, African Governance and Development Institute Working Paper (No.15/011,Yaoundé.)

Castellini, M. and Agyemang, O. (2012). Ownership and Board Structures to Ensuring Effective Corporate Governance through Ownership and Board Control Systems", Corporate Ownership and Control, vol. 9, No. 2, pp. 336-343

Chalevas, C. and Tzovas, C. (2010). The effect of the mandatory adoption of corporate governance mechanisms on earnings manipulation, management effectiveness and firm financing Evidence from Greece, Managerial Finance, Vol. 36 No. 3, pp. 257-277

Chauhan, Y., Lakshmi, K. and Dey, D. (2016). Corporate governance practices, self-dealings, and firm performance: Evidence from India, Journal of Contemporary Accounting \& Economics, 12, pp 274-289

Chizema, A. (2010). Early and late adoption of American-style executive pay in Germany: Governance and institutions, Journal of World Business, 45, pp 9-18

Devaney, L. (2016). Good governance? Perceptions of accountability, transparency and effectiveness in Irish food risk governance, Food Policy, 62, pp 1-10

Fanta,A., Kemal, K. and Waka, Y. (2013). Corporate governance and impact on bank performance, Journal of Finance and Accounting, 1(1), pp 19-26

Furmankiewicz, M. and Walsh, A. (2016). Government within governance? Polish rural development partnerships through the lens of functional representation, Journal of Rural Studies, 46, pp 12-22.

Gupta, K Krishnamurti, C. and Tourani-Rad, A. (2018). Financial development, corporate governance and cost of equity capital, Journal of Contemporary Accounting \& Economics 14, pp 65-82

Gyamfi, M., Bokpin, G. and Gemegah, A. (2015). Corporate governance and transparency: evidence from stock return synchronicity, Journal of Financial Economics, Vol. 7, No.2, pp 157-179

Ilukora, J., Birnera, R. and Nielsena, T. (2015). Addressing governance challenges in the provision of animal health services: A review of the literature and empirical application transaction cost theory, Preventive Veterinary Medicine, 122 pp 1-13

Institute of Internal Auditor of Netherlands (2016), The Governance Challenges

Kisingo, A., Rollins, R., Murray, G., Dearden, P. and Clarke, M. (2016). Evaluating good governance: The development of a quantitative tool in the Greater Serengeti Ecosystem, Journal of Environmental Management, 181, pp 749-755

Lamm, J. (2010). The Rise of Governance: Governance Across the Enterprise. New York: CA, Inc

Larcker, D., and Tayan, B., (2011). Corporate Governance Matters. Pearson Education Inc., Upper Saddle River, NJ, USA

Muller, R., Zhai, L., Wang, A. and Shao, J. (2016). A framework for governance of projects: Governmentality, governance structure and projectification, International Journal of Project Management, 34, pp 957-969

Nofiantia, L. and Susenob, N. (2014). Factors affecting implementation of good government governance (GGG) and their implications towards performance accountability, Procedia - Social and Behavioral Sciences, 164 pp 98 - 105 
Ojo, A. and Mellouli, S. (2016). Deploying governance networks for societal challenges, Government Information Quarterly, Article in Press

Okpara, J. (2011). Corporate governance in a developing economy: barriers, issues, and implications for firms, Corporate Governance: The international journal of business in society, Vol. 11 Iss 2, pp. 184 - 199

Pittman, J. and Armitage, D. (2016). Governance across the land-sea interface: A systematic review, Environmental Science \& Policy, 64, pp 9-17

Tan, S., Habibullah, M. and Tan, S. (2017). Corporate Governance and Environmental Responsibility, Annals of Tourism Research, Article In Press

Termeer, C., Vinkhuyzen, A. and Vliet, M. (2016). Coping with the wicked problem of climate adaptation across scales:The Five R Governance Capabilities, Landscape and Urban Planning, 154, pp 11-19

Tofan, M. Bercu, A. and Cigu, E. (2015). Corporate governance framework in Romanian companies, Procedia Economics and Finance, 20, pp $629-636$

Tricker, B. (2012). Corporate Governance: Principles, Policies, and Practices, Second ed. Oxford University Press, UK, Oxford, UK

Turner, R., Fitzsimmons, C., Forster, J., Mahon, R. Peterson, A. and Stead, S. (2014). Measuring good governance for complex ecosystems: Perceptions of coral reef-dependent communities in the Caribbean, Global Environmental Change, 29, pp 105-117

Zabi, S., Ahmad, K. and Wah, K. (2016). Corporate Governance Practices and Firm Performance: Evidence from Top 100 Public Listed Companies in Malaysia, Procedia Economics and Finance 35, pp 287 - 296 